\title{
LA EMBLEMÁTICA FUENTE DE TRONCOSO (MONDARIZ, PONTEVEDRA) Y LA INACCIÓN QUE HA CONDUCIDO A LA RUINA DE ESTE SOBRESALIENTE PATRIMONIO MINERO
}

\author{
THE EMBLEMATIC SPRING OF TRONCOSO (MONDARIZ, \\ PONTEVEDRA) AND THE INACTION WHICH HAS LET TO THE \\ DESTRUCTION OF THIS OUTSTANDING MINING HERITAGE
}

\author{
Enrique Orche García ${ }^{1}$, María Pilar Amaré Tafalla \\ ${ }^{1}$ Sociedad Española para la Defensa del Patrimonio Geológico y Minero
}

\section{RESUMEN}

El presente trabajo tiene por objetivo demostrar cómo la inacción de las instituciones responsables de conservar la fuente han conducido a su ruina. Para ello se relata el proceso por el que la fuente de agua mineromedicinal de Troncoso, bien cultural y patrimonio minero, se ha ido degradando hasta llegar a un estado ruinoso agravado en 2019 cuando se hundió parcialmente la techumbre del edificio que la alberga. Las medidas previstas para atajar dicha degradación desde el año 2002 hasta el presente, casi nunca llevadas a la práctica, no han resuelto el problema demostrándose una ineficaz gestión cultural tanto de los propietarios como de las administraciones públicas. Determinados compromisos institucionales parecen apuntar a la rehabilitación de la fuente, pero están pendientes de ciertos trámites burocráticos que suelen ser muy lentos. Mientras tanto, los vecinos, hartos de la ineficacia de unos y otros, han decidido tomar la iniciativa por su cuenta y, en la medida de sus posibilidades, adecentar y cuidar tan emblemático bien patrimonial por su cuenta. El trabajo se ha documentado en base a estudios previos y a la consulta sistemática de los medios de comunicación que han dado noticia de los hechos.

Palabras Clave: agua, patrimonio, Mondariz, Troncoso

\begin{abstract}
This paper has the aim of showing how inactivity of responsible institutions for preserving the fountain have led it to collapse. For that, it describes the process by which the mineral water spring of Troncoso, a cultural and mining heritage, has deteriorated to its present dilapidated condition worsened in 2019 when the roof of the building that houses partially sank. The measures envisaged to prevent degradation since 2002 to the present, almost never put into practice, they have not solved the problem proving ineffective cultural management both owners and public administrations. Certain institutional commitments seem to point to the rehabilitation of the source but are pending certain bureaucratic procedures that can be very slow. Meanwhile, neighbours, fed up with the inefficiency of each other, have decided to take the initiative to clean up and care as emblematic heritage site on their own. This paper has considered prior studies and the notices of news media that have notified the facts.
\end{abstract}

Key words: water, heritage, Mondariz, Troncoso 


\section{Introducción}

En un artículo anterior (Orche, Amaré, Orche, 2015) los autores relataron la historia de la fuente de Troncoso, su sobresaliente incidencia en la creación del emblemático Balneario de Mondariz (Pontevedra), en su día uno de los más importantes de España y, posiblemente, de Europa, y el lamentable estado en que ya estaba sumida en 2014.

Los años transcurridos desde esta fecha hasta 2019 han supuesto un progresivo deterioro de las condiciones de la fuente, abandonada a su suerte en lo tocante a su mantenimiento, hasta que el día 9 de abril, los diarios del área de Vigo (Pontevedra) informaban de que la techumbre de uno de los dos cuerpos en que está dividida se había derrumbado completamente. Era un desenlace anunciado, fácilmente predecible.

El presente artículo pretende poner de manifiesto cómo la inacción del propietario (Balneario de Mondariz) y de las autoridades han conducido a la deplorable situación actual de la fuente, completamente inexplicable a tenor de la importancia que tuvo en su día, tanto para sus dueños como para el municipio (Mondariz primero y Mondariz Balneario desde 1924).

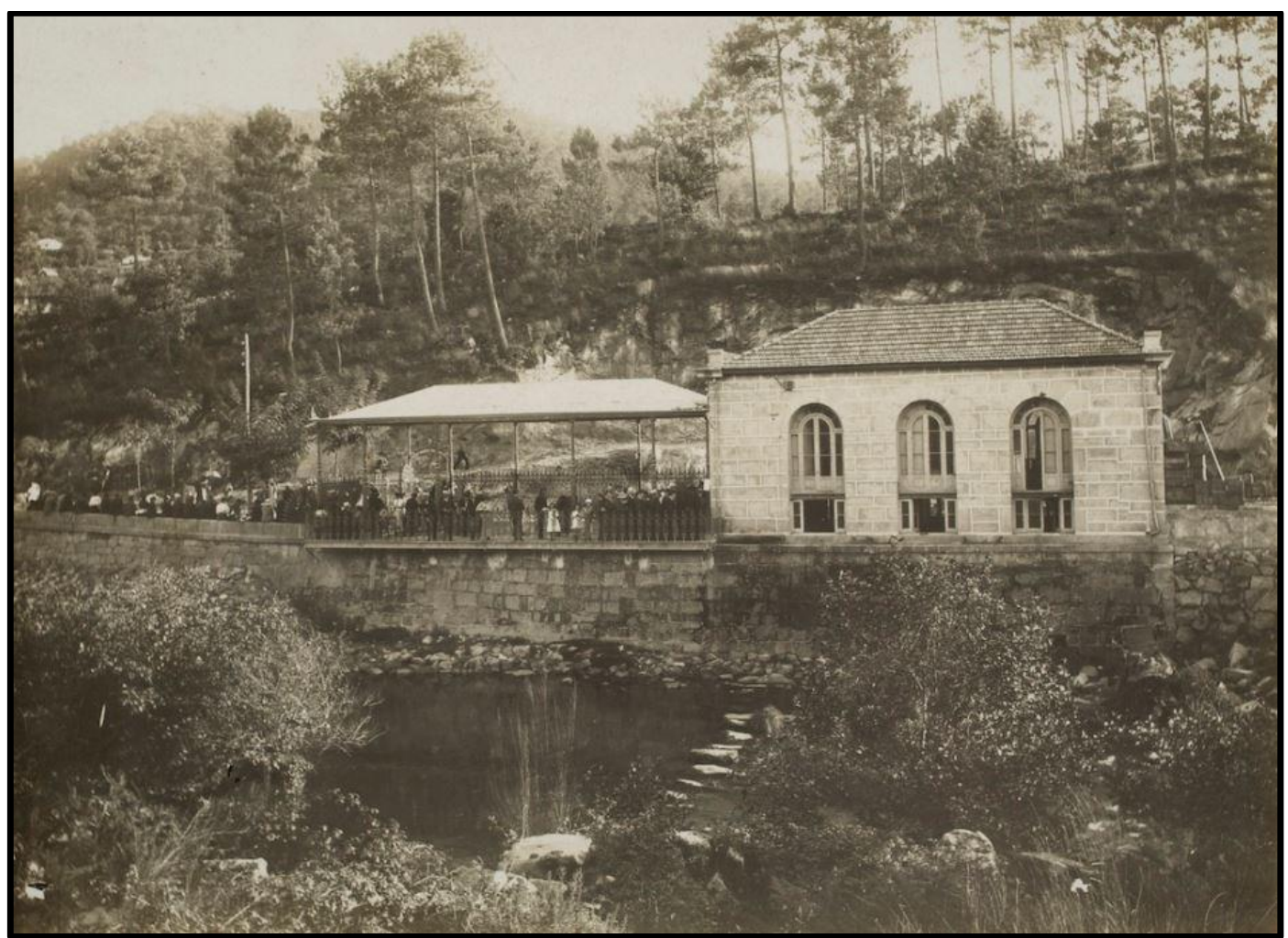

Fig. 1 Fuente de Trocoso hacia 1910, con la planta situada a la derecha y el manantial en el interior de un segundo cuerpo ubicado en la parte izquierda. Fuente: Concello de Mondariz Balneario, s/f

Pese al emblemático papel jugado por Troncoso durante años, a la calidad y uso que la población hizo y hace de su agua, a que fue edificada por el emblemático arquitecto Antonio Palacios y a que está ubicada en un lugar paradisíaco a orillas del río Tea, en el que hace unos años se construyó un largo paseo que permite acceder a la fuente con toda comodidad y disfrutar del lugar, los propietarios de la misma se han despreocupado de atajar su lamentable deterioro reparando solo los elementos que, en determinadas ocasiones, resultaban peligrosos para los agüistas que pudieran entrar a beber agua al manantial. Desafortunadamente, sólo han sido parches que han retrasado el lento deterioro de la fuente. 
El edificio de Troncoso consta de dos cuerpos, uno que alberga la fuente y otro anexo que contenía la planta embotelladora (Figura 1). Mientras que el primero se ha mantenido accesible al público, el segundo se cerró a cal y canto sin haberse programado un uso complementario al de la fuente. Precisamente este segundo cuerpo ha sufrido cuantiosos daños como resultado del derrumbe completo de la techumbre que ha arrasado el interior de las dos plantas de que consta, aunque, milagrosamente, no ha afectado al muro que lo separa de dicha fuente. De la antigua planta sólo ha quedado el muro perimetral.

El objetivo del presente artículo radica en explicar las iniciativas, inacciones y complejidades administrativas que han llevado a la ruina actual de las instalaciones. Estos hechos están relativamente bien documentados, por lo que se puede seguir la sucesión de acontecimientos que han conducido, finalmente, a la ruina de las mismas y, llegada a esta situación, a su necesidad de rehabilitación. No se conocen antecedentes que aborden la cuestión planteada en este artículo pues, hasta el presente, los trabajos sobre Troncoso se han limitado a relatar su historia e importancia sanitaria y social (por ejemplo, Pérez, 2005).

\section{El manantial de Troncoso}

El primer escrito que hace referencia a la surgencia de agua mineral junto al río Tea data de 1772, en la "Descripción de 54 fuentes minerales del Reyno de Galicia", escrita por Pedro Gómez de Bedoya (1772). En ella describía el agua como clara, fría, maloliente, de sabor picante y poco grato, que dejaba una pátina de mucosa ferruginosa que teñía las piedras. Sin embargo, las peculiares características del agua y la existencia en la zona de restos romanos sugieren que, posiblemente, esta agua era conocida desde dicha época, aunque todavía no se han encontrado evidencias arqueológicas que lo demuestren.

Para encontrar una segunda referencia al manantial de Troncoso hay que esperar a 1848, año en que Pascual Madoz lo cita en su "Diccionario Geográfico Estadístico Histórico de España y sus posesiones de Ultramar". En él indica que el agua era de naturaleza nitrosa y servía para curar enfermedades de la piel, aunque aclaraba que nunca había sido analizada (Madoz, 1848).

El inicio del aprovechamiento del agua de Troncoso data de 1862, cuando el párroco local, Domingo Blanco, descubrió sus propiedades salutíferas al compararlas con las de las aguas del manantial de Monçao, en el norte de Portugal, ya entonces famosas por sus bondades curativas. El hecho es que un enfermo que se había tratado con éxito en Monçao sus dolencias estomacales preguntó al cura si sabía de algún remedio que pudiera aliviarle los dolores que en esa época padecía. Blanco recordó la similitud de las propiedades físicas de ambas aguas y le recomendó beber del manantial de Troncoso. El enfermo siguió su consejo y en dos meses se curó. Blanco repitió el tratamiento con otras personas que presentaban los mismos síntomas, obteniendo resultados análogos. La curiosidad científica del párroco le llevó a mandar analizar las aguas al farmacéutico de Puenteareas, Antonio Álvarez, cuyos resultados mostraron que las aguas de Troncoso eran similares a las de Verín (Orense) y Vichy (Francia), ambas de reconocido prestigio. Esta noticia tuvo una gran difusión de manera que, llegada a oídos del obispo de Tuy, Telmo Maceira, envió al farmacéutico Antonio Rodríguez y al médico Ramón Parcero para que examinaran las aguas de Troncoso, los cuales confirmaron los resultados obtenidos por Antonio Álvarez. Sin embargo, Blanco, para confirmar la naturaleza y propiedades del agua, en 1864 encargó un segundo análisis a la Universidad de Santiago, concretamente a los catedráticos de Química, Antonio Casares, y de Medicina, Maximino Teijeiro, cuyos resultados avalaron los obtenidos previamente. La descripción de las propiedades físicas coincidía plenamente con la de Pedro Gómez de Bedoya de 1772 mientras que, desde el punto de vista químico, Casares las clasificó como bicarbonatado-sódicas, ferruginosas y alcalinas (Orche, Amaré, Orche, 2015).

Tras diversas vicisitudes que se comentan ampliamente en el trabajo citado de 2015, el manantial pasó a manos de Enrique Peinador, médico que investigó en la zona la presencia de manantiales de agua medicinal para construir y poner en explotación un balneario. Por su iniciativa, el agua de la fuente de Troncoso fue declarada de utilidad pública el 18 de junio de 1873 y, como tal, comenzó a emplearse con fines terapéuticos. 
Las aguas de Troncoso estaban clasificadas como bicarbonatadas sódicas, variedad ferruginosa, siendo indicadas de forma general para infartos de las vísceras abdominales, catarro vesical, diabetes sacarina y algunas manifestaciones gotosas. Específicamente estaban recomendadas para gastralgia, dispepsias ácidas y flatulentas, diátesis úrica, clorosis y cálculos biliares (Ruiz et al, 1877).

Peinador había descubierto cerca de ella otra fuente cuyas aguas eran de las mismas características que Troncoso, el manantial de Gándara, que también adquirieron con la idea de aprovechar ambas en un balneario común. Sin embargo, el Ayuntamiento de Mondariz pleiteó por la propiedad de Troncoso durante treinta y tres años, aunque, finalmente, la Justicia falló que la fuente pertenecía a los Peinador. Debido al pleito, la creación del nuevo balneario tuvo que basarse en las aguas de Gándara. Pese a que la situación legal de Troncoso estaba inmersa en un interminable pleito, seguía recibiendo agüistas y proporcionando grandes cantidades de agua para embotellar y enviar al extranjero. Lamentablemente, la falta de mantenimiento por parte de los reclamantes de los derechos sumió la fuente en un estado de semi-abandono. Cuando en 1905 la justicia concedió definitivamente la propiedad de Troncoso a los Peinador, rápidamente modernizaron sus instalaciones, encargando al acreditado arquitecto pontevedrés Antonio Palacios, coautor del Palacio de Comunicaciones de Madrid, el diseño y construcción de un pabellón que se conserva hasta hoy y que es el objetivo de este trabajo.

\section{La fuente de Troncoso, patrimonio cultural industrial y minero}

Como se ha indicado, el agua de la fuente de Troncoso fue catalogada como minero medicinal en 1873, por lo que está incluida en las sustancias a las que se aplica la Ley 22/1973, de 21 de julio, de Minas, según sus artículos 3.b y 23a. Por otra parte, Troncoso entra dentro de la definición de patrimonio industrial, en el que se incluye el minero, que preconizan la "Carta de Nizhny Tagil sobre patrimonio industrial" de TICCIH del 17 de julio de 2003 (The International Committee for the Conservation of the Industrial Heritage/TICCIH, 2003) y los "Principios de Dublín" elaborados conjuntamente por ICOMOS-TICCIH de 28 de noviembre de 2011 (International Council on Monuments and Sites/ICOMOS y TICCIH, 2011). De la misma forma, el Ministerio de Educación, Cultura y Deporte de España, en su "Plan Nacional de Patrimonio Industrial, actualización de 2015" (Ministerio de Educación, Cultura y Deporte, 2015) permite incluir a Troncoso como elemento industrial del patrimonio inmueble. De hecho, el propio pabellón de la fuente, diseñado por el afamado Antonio Palacios, constituye en sí mismo un valioso ejemplo de arquitectura industrial y de esta forma ha sido considerado por los especialistas que han tenido oportunidad de conocerlo. El edificio consta de dos cuerpos de planta rectangular (Figuras 1 y 7), uno dedicada a albergar una planta embotelladora y otro la fuente. Ambos constan de planta baja y sótano. El primero está delimitado por una fachada de granito dos de cuyas paredes están horadadas por tres grandes ventanales en forma de arco de medio punto. Los muros están rematados por un pretil y sus esquinas se han reforzado con pilares. El segundo cuerpo, el que alberga la fuente, es diáfano y está cubierto por una marquesina. El recinto está cerrado por una artística verja de hierro forjado. En el interior, un pasillo en voladizo sobre la planta inferior está limitado por la citada verja y una barandilla de forja que se abre en dos escaleras que forman sendos arcos. Por medio de ellas se desciende al piso inferior en el que se encuentra el manantial. Allí se ha construido una barandilla ondulada que separa de la zona baja en la que se encuentra la fuente. Las líneas curvas del interior de este cuerpo crean una sensación de amplitud espacial que compensa su reducido tamaño. La marquesina que cubre el manantial y la verja perimetral fueron trasladadas desde la vecina fuente de Gándara, cuando en esta misma época fue ampliada por el propio Antonio Palacios (Pérez, 2005). El estudio de arquitectura Merz que recibió el encargo de restaurar la fuente la describe de la siguiente manera:

"La fuente es un hermoso ejemplo de lo que podríamos considerar como una arquitectura del hierro local. Mediante la formación de una malla triangular a base de la repetición de piezas triangulares y motivos ornamentales de fundición, se construye una estructura que forma un delicado encaje de apariencia 
extraordinariamente ligera. Esta delicada estructura, completamente regular, queda toscamente embebida en los muros del recinto, que no son ortogonales" (Merz Arquitectos, 2014).

Por otra parte, la fuente de Troncoso se sitúa a orillas del río Tea, en un lugar solitario rodeado de un denso bosque de ribera, en el que el agua y la vegetación producen al visitante una sensación relajante. A ello contribuye también la belleza del sitio pues el paisaje local se caracteriza por las suaves formas del relieve, las arboledas y pastos, el río y sus sonidos y umbrías, todo lo cual añade atractivo a la fuente y su entorno. El papel jugado por la población rural en donde se sitúa Troncoso tampoco puede desdeñarse; desde que en 1862 sus aguas adquirieron carta de naturaleza cuando el párroco local, Domingo Blanco, descubrió sus propiedades salutíferas, nunca han dejado de utilizarse por la población de la zona, que la tuvo y la tiene por medicina eficaz y gratuita. A Troncoso se debe el crecimiento del vecindario rural de la mano tanto de su utilización balnearia que mantuvo la población local como del negocio balneario y hotelero que compatibilizaban con los trabajos agropecuarios tradicionales. A esta actividad no fue ajeno el Balneario de Mondariz, que adquirió la vecina finca de Pías como fuente de suministro de productos agrícolas y ganaderos para abastecer a los agüistas alojados en el hotel, en la que, además, construyó un museo etnográfico y arqueológico que constituía uno de los atractivos culturales locales.

La singularidad de la fuente de Troncoso ha sido reconocida por el Ayuntamiento de Mondariz-Balneario al incluirla en el "Catálogo de Elementos Protegidos" como Bien Cultural en Arquitectura Civil y también en el "Catálogo de Bienes Patrimoniales del Plan General de Ordenación Municipal" con el n² 24, cuya aprobación inicial data del 13 de agosto de 2012. En conclusión, cabe señalar que, por una parte, el agua de Troncoso está reconocida como producto de carácter netamente minero mientras que, por otra, la fuente, por sus características, constituye una evidencia de la extracción de un material industrial como es el agua propiamente dicha. A mayor abundamiento, el cuerpo del pabellón que alberga la fuente y su espacio inmediato presentan unos valores constructivos, estéticos, paisajísticos y etnográficos que reflejan la profunda relación existente entre los entornos cultural y natural de Mondariz Balneario, y de ellos con los de otras partes de España y del extranjero. En resumen, puede asegurarse que la fuente de Troncoso es un bien de patrimonio cultural, industrial y minero sin que quepa ningún género de dudas.

\section{Problemas y actuaciones (2002-2018)}

Desde la rehabilitación de Troncoso, concluida por Antonio Palacios en 1910, la fuente ha prestado un servicio público continuado, pero se ha ido deteriorando de forma lenta y progresiva sin que ni el propietario ni las administraciones públicas hayan adoptado medida efectiva alguna. Se ignora desde cuándo se han dado estas circunstancias, aunque, posiblemente, pudieron comenzar en 1973, a raíz del incendio, destrucción y cierre temporal del Balneario de Mondariz. Si bien desde 2002 consta la realización de propuestas para recuperar tan significativo patrimonio cultural y minero, ninguna de ellas tuvo éxito. Entre estos fallidos intentos cabe destacar la siguiente relación de hechos y situaciones. En 1997 comenzó su actividad la Fundación Mondariz Balneario (Orden de 10 de junio de 1997), institución sin ánimo de lucro orientada a la difusión de la cultura y valores sociales. Su ideario era tomar el municipio de Mondariz Balneario, el más pequeño de España, como referencia para un renovado impulso cultural, devolviendo a la villa su papel de foro económico y social que la singularizó. Esta institución propuso algunas iniciativas para la recuperación de la fuente.

El Proyecto de Ordenación del Medio Rural de Mondariz Balneario de 2001 y su posterior primera modificación puntual de 2002, apostaba por mejorar y clarificar las condiciones del patrimonio cultural del municipio y ampliar el Catálogo de bienes protegidos, así como mejorar y clarificar las ordenanzas y condiciones específicas de edificación en las distintas categorías de suelo. En dicho Catálogo de Bienes Culturales municipales se incluían las fuentes de Gándara y Troncoso como elementos significativos con protección integral. Por tanto, a partir de esa fecha Troncoso es considerada bien cultural municipal con el máximo grado de protección (Consultora Galega, 2016b). La modificación no preveía cambio de uso con lo que continuaría siendo el que estaba 
desarrollando hasta ese momento (Consultora Galega, 2016a), es decir, abierta para uso público de su manantial.

El casi simultáneo Proyecto de Ordenación del Rural Propio (PORP) municipal planteó en 2002 una propuesta para recuperar el edificio de Troncoso que no se llevó a cabo (Orche, Amaré, Orche, 2015). La situación de Troncoso se degradaba por momentos a causa de los embates climatológicos estacionales normales, en alguno de los cuales el rio Tea se desbordaba llegando el nivel de sus aguas a la cota del vial de acceso a la fuente. Un esquema del proceso se aprecia en la Figura 2 sobre un perfil del edificio de Palacios. La Figura 3 muestra la situación de la fuente respecto del río en momentos de inundación mientras que la Figura 4 corresponde a ese mismo instante en el interior del pabellón, con la surgencia cubierta por el agua. En estos casos, al bajar el agua a su nivel normal, la herrumbre cubría las partes metálicas no protegidas; además, la instalación quedaba revestida de una capa de lodo que había que limpiar. Así ocurrió, por ejemplo, en 2006 en el que el nivel del agua prácticamente alcanzó el del paseo de acceso a la fuente, como se aprecia en las citadas figuras.

La Diputación de Pontevedra tuvo una magnífica oportunidad para rehabilitar Troncoso que, lastimosamente, se perdió. En 2008 presentó al plan de ayudas del Fondo Europeo de Desarrollo Regional (FEDER) de la Comunidad Europea un proyecto de recuperación medioambiental de las márgenes del río Tea, en el tramo Ponteareas a Mondariz Balneario, Mondariz y Covelo que incluía financiación de la Diputación de Pontevedra y de los Ayuntamientos.

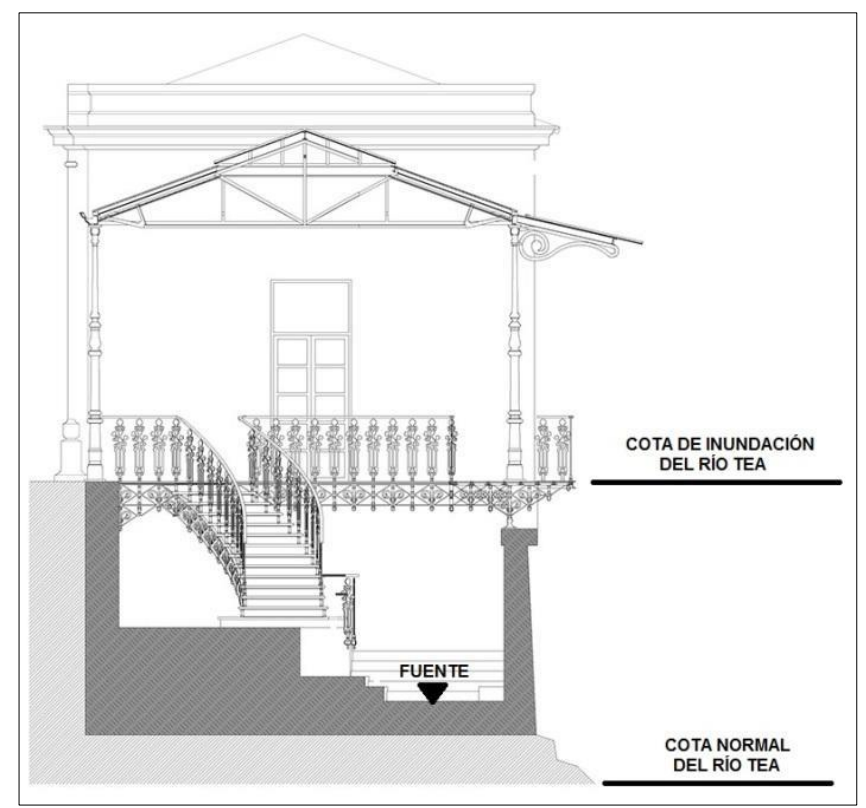

Fig. 2 Niveles de río Tea normal y en inundación. Fuente: Merz Arquitectos, 2014. Modificada 


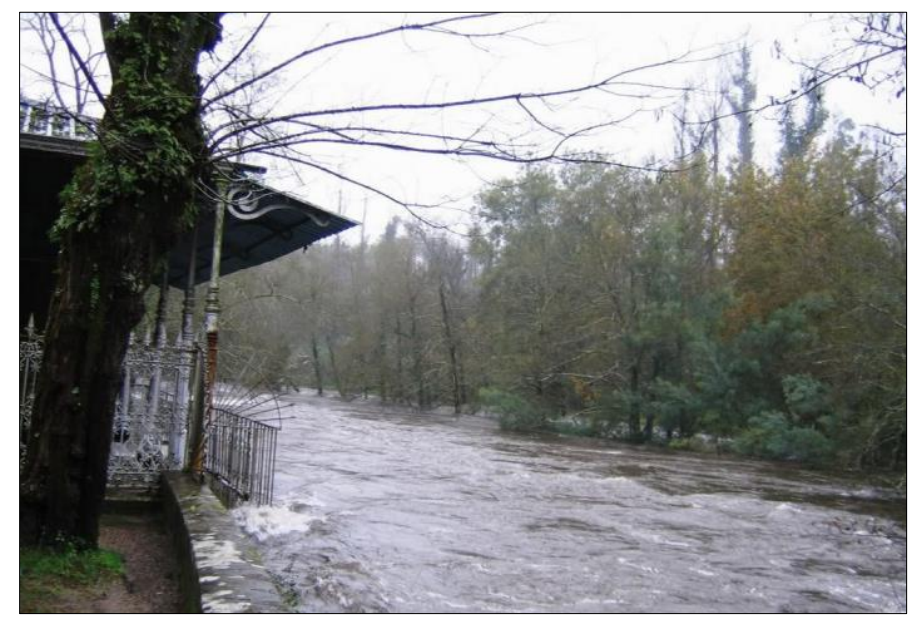

Fig. 3 Nivel de inundación del río Tea. Anónimo, 2006a

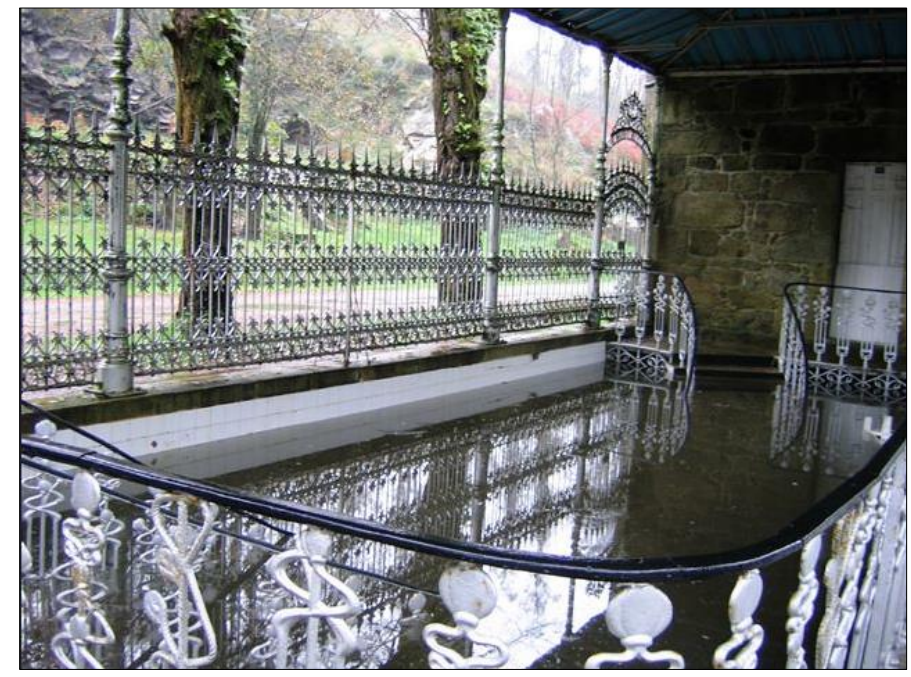

Fig. 4 Inundación del interior de la fuente de Troncoso. Fuente: Anónimo, 2006b

El citado proyecto contemplaba el desarrollo de una senda fluvial en el río Tea atravesando dichos municipios con delimitación para carril para bicicletas, áreas de descanso, fuentes, papeleras, paneles informativos, alumbrado público y bancos para descanso (Porto, 2008). Lamentablemente Troncoso quedó fuera de la intervención.

El 17 de noviembre de 2009 se integraron en el patronato de la Fundación Mondariz Balneario, su órgano de dirección, instituciones públicas como la Consellería de Cultura e Turismo, la Diputación Provincial de Pontevedra y el Concello de Mondariz Balneario, así como las empresas Aguas de Mondariz y Balneario de Mondariz (Fundación Mondariz Balneario, 2009). En la Memoria de Actividades de 2010, la Fundación reconocía la "difícil situación de esta fuente centenaria, símbolo y razón de visitas a este entorno, que se ha convertido en debate político municipal" (Fundación Mondariz Balneario, 2011, s.p), aunque le atribuía el mérito de atraer visitas al pueblo. En dicha Memoria informaba de que el asunto de Troncoso ya se había convertido en tema de debate político municipal, y daba a conocer que había preparado una propuesta para rehabilitar la fuente que incluía:

- Análisis de riesgos de la instalación, con recomendación de mantenerla cerrada.

- Propuesta de actuación, con tres presupuestos alternativos. 
- Transformación de la fuente en un punto de hostelería emblemático, para lo que se contaba con un futuro operador.

Por otra parte, la Fundación solicitaba a la Diputación de Pontevedra que, como patrono, concretara sus aportaciones, quedando pendiente de su respuesta, y preveía que el año 2011 sería clave para la rehabilitación de Troncoso (Fundación Mondariz Balneario, 2011).

Consciente de la deteriorada situación de la misma, la Fundación Mondariz Balneario solicitó un informe técnico en 2010 cuyos autores llegaron a la conclusión de que había riesgo de que se hundiera el tejado. Esto era una gran responsabilidad para la empresa propietaria, por lo que la Fundación se puso en contacto con el Ayuntamiento y se comprometió a arreglarlo ese mismo año. Javier Solano, presidente de la citada Fundación y del Balneario de Mondariz informaba de que los propietarios de la fuente habían invertido mucho dinero en el lugar pero que "el paso del tiempo y los numerosos actos de vandalismo hicieron su efecto" (Anónimo, 2011, s.p). Asimismo, la Fundación notificó que había firmado un compromiso con la Xunta de Galicia y la Diputación de Pontevedra para que colaborasen económicamente en la restauración de Troncoso pero que, en esos momentos, el proyecto FEDER del río Tea no contemplaba el arreglo de la fuente cuya reparación debía esperar tiempos mejores; el importe de esta intervención sería de $120.000 €$, aproximadamente. La Fundación anunció que realizaría una reparación transitoria que empezaría en unas semanas. La fuente de Troncoso estuvo cerrada debido a su lamentable estado de conservación y solo se abrió en julio y agosto debido a la presión de los vecinos que reivindicó su uso durante esos meses (Anónimo, 2011). De hecho, en este mismo año de 2010 se colocaron unos puntales para sostener la techumbre. Aun así, mientras la fuente permaneció cerrada, las puertas exteriores del pabellón fueron forzadas por la gente que seguía acudiendo a tomar el agua. Los concejales municipales nacionalistas de la oposición criticaban "la inoperancia y falta de iniciativa del Ayuntamiento y la dejadez de la empresa propietaria en la preservación y valorización de un bien patrimonio de toda la ciudadanía" (Porto, 2010, s.p). Igualmente, se quejaban de que las inversiones públicas que permitieron acondicionar el entorno de la fuente no tuvieron la contrapartida de la reparación de la fuente por parte de su propietario, el Balneario de Mondariz. Los nacionalistas propondrían la cesión de la propiedad del edificio al Ayuntamiento para que éste asumiera su rehabilitación (Porto, 2010, s.p.).

En el año 2011 Aguas de Mondariz y Aguas de Galicia anunciaron la concesión de $1.700 .000 €$ por los Fondos FEDER solicitados años antes para la recuperación de la senda que recorría el río Tea por los municipios de Mondariz, Mondariz Balneario y Puenteareas a lo largo de más de $7 \mathrm{~km}$. El presupuesto total del proyecto era de 2.300.000 $€$, incluyendo las aportaciones de las administraciones públicas gallegas. Lamentablemente, aunque estaba prevista la restauración de puentes y molinos, no comprendía intervención alguna en la fuente de Troncoso, entonces ya con graves problemas en su estructura y amenaza de ruina. En esos momentos estaba cerrada todo el año excepto los meses de julio y agosto debido a la afluencia de agüistas (Anónimo, 2011). En dicho año el techo del pabellón seguía sostenido con puntales y su interior presentaba el mismo grado de deterioro que en 2010.

En este mismo 2011, la Fundación Mondariz Balneario encargó al estudio Merz Arquitectos, de Madrid, un proyecto de rehabilitación del pabellón. Dicho proyecto planteaba abrir un ventanal en el muro situado a lo largo del río y construir un suelo de vidrio en la planta de acceso que nunca tuvo (Merz Arquitectos, 2014). Con esta propuesta se desvirtuaba el lugar respecto de cómo fue diseñado y construido por Antonio Palacios, sin añadir ninguna mejora que la justificara. De hecho, tales añadidos contravenían las recomendaciones internacionales de ICOMOS y TICCIH y las nacionales del Plan Nacional del Patrimonio Industrial, que se basa en ellas, sobre la rehabilitación de este tipo de bienes. Por motivos que se ignoran, el proyecto de Merz Arquitectos no se llegó a realizar.

Las Memorias de la Fundación correspondientes a los ejercicios de 2011, 2012 y 2013 no hacían referencia a la fuente de Troncoso, aunque, en febrero de este último año, el estado del conjunto era francamente preocupante con las puertas rotas, el interior cubierto de barro y la fuente inundada. La situación había 
empeorado más aún el 4 de abril de 2013, ya que la fuente estaba completamente anegada. Como dato positivo cabe señalar que en este mismo año ya se había realizado la reparación del tejado correspondiente a la parte del edificio que albergaba el manantial y se habían eliminado los puntales que lo sostenían. Sin embargo, las puertas y ventanas del edificio anexo (la antigua planta embotelladora) estaban tapiadas con ladrillos, y su conexión con la fuente, cerrada con un tabique.

La verja de la fuente, en agosto de 2014, estaba deliberadamente abierta y el público, entraba libremente a beber el agua o a recogerla en botellas. El interior había sido limpiado de barro, pero presentaba un deplorable aspecto: las escaleras apuntaladas, los suelos llenos de grietas, los baldosines de las paredes desconchados, las barandillas sin pasamanos o con ellos rotos, las barras de acero del armado del hormigón de la estructura al descubierto y oxidadas, las barandillas con muchas varillas originales sustituidas por otras de cuadradillo 0 de acero corrugado, las partes metálicas como verjas y columnas, oxidadas, etc. Las quejas y lamentaciones oídas a los agüistas ocasionales sobre el estado de la fuente daban pábulo a pensar en la inmensa satisfacción que ellos y, por extensión, el resto de los habitantes y visitantes del pueblo, tendrían si se restaurara la fuente a su pasado esplendor.

Pocos meses más tarde, en noviembre de 2014, se hizo público que la situación financiera del Balneario de Mondariz era preocupante, hecho que en lo sucesivo tendría importantes repercusiones para la fuente de Troncoso. En dicho mes la empresa presentó solicitud de concurso voluntario de acreedores, pues hacía varios años que tenían gran dificultad para atender el elevado importe de la deuda bancaria contraída para financiar la reconstrucción del balneario en la década de 1990. Afortunadamente el proceso se desarrolló en menos de un año, pues en 2015 , contando con la conformidad de la plantilla y el respaldo de la Seguridad Social, la mayoría de los acreedores se adhirieron al plan de viabilidad presentado por la empresa, y se estaba concluyendo la negociación con las entidades financieras y las administraciones públicas para completar el plan de reordenación del total de la deuda (Anónimo, 2015). No obstante, a pesar de la complicada situación económica, no estuvo comprometida la actividad ordinaria del establecimiento y de su plantilla, que mantuvo una elevada ocupación y trabajó con absoluta normalidad en el balneario (Anónimo, 2014).

Precisamente en 2015 vería la luz un informe sobre la unidad del conjunto del Hotel Balneario de Mondariz, elaborado por el Consello da Cultura Galega. En el mismo se consideró que, dentro de dicho conjunto, estaba incluida la fuente de Troncoso y que su significación cultural, y la del paseo que lleva hasta ella, estaban ligadas a la del balneario. Teniendo en cuenta el valor del conjunto, el Consello propuso que todo él, incluida la fuente, fuera considerado e inscrito en el Registro de Bienes Culturales (BIC) en la categoría de Conjunto Histórico (Consello da Cultura Galega, 2015). Era un nuevo respaldo a la importancia de Troncoso.

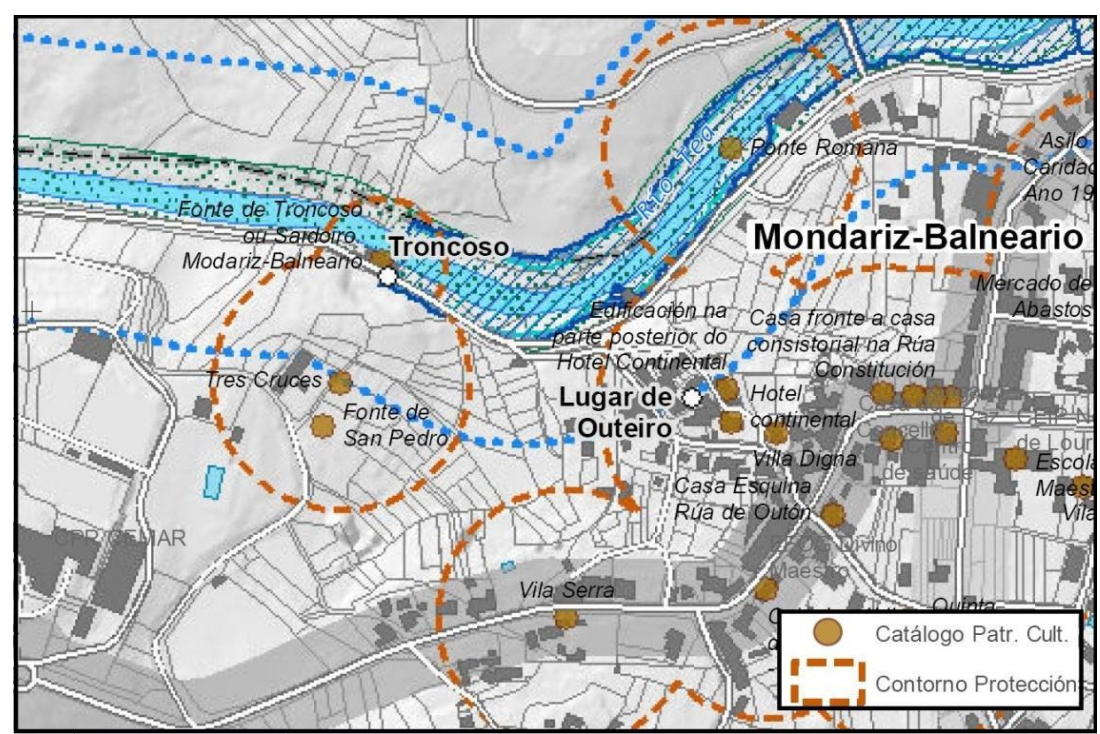


Fig. 5 Troncoso y su perímetro de protección como patrimonio cultural. Fuente: Elaborado por el autor con datos de Plan Básico Autonómico. Xunta de Galicia (2018). Mapa de afeccions territoriais, Hoja 0224A-0206. Modificado

Ya en 2106, la Xunta de Galicia promulgó una actualización de la Ley de Patrimonio Cultural de Galicia, la Ley 5/2016 (Xunta de Galicia, 2016), al amparo de la cual elaboró el Plan Básico Autonómico (PBA). Este plan constituye un instrumento de planificación urbanística que complementa el nuevo marco urbanístico con el que el gobierno de la Xunta pretende impulsar una ordenación responsable y sostenible del territorio, con el propósito de garantizar su disposición y desarrollo ordenados. Fue presentado para su uso público interactivo en 2018 (Xunta de Galicia, 2018). En dicho PBA, la fuente de Troncoso fue catalogada en el citado año como patrimonio cultural etnográfico compartiendo perímetro de protección con la vecina fuente de San Pedro (Figura 5).

De acuerdo con el art. 32 de la Ley 5/2016, una vez que la Xunta de Galicia ha catalogado un bien como patrimonio cultural, los propietarios de dicho bien están obligados a conservarlo, mantenerlo y custodiarlo debidamente y a evitar su pérdida, destrucción o deterioro. El art. 33 establece que la Xunta podrá acordar medidas de colaboración con otras administraciones nacionales o con organismos internacionales que fortalezcan y mejoren la vigilancia y la seguridad de los bienes que integran el patrimonio cultural de Galicia, especialmente cuando se vean amenazados por actos de expolio o destrucción. Esta posibilidad podría permitir al Ayuntamiento de Mondariz Balneario tener una mayor presencia en la vigilancia y protección de la fuente. De esta forma, desde el 26 de julio de 2018, Troncoso goza oficialmente de un nivel de protección oficial suficiente para garantizar su conservación, habiéndose definido el marco legal para llevar a efecto las medidas correctoras que, en su caso, hubiera que adoptar, y establecer quiénes serían los intervinientes en dicho proceso.

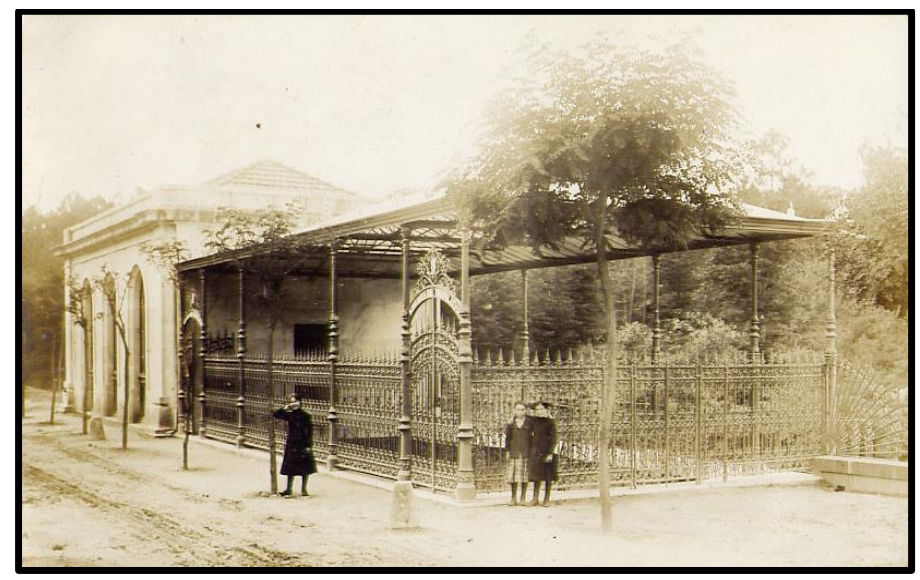

Fig.6 Fuente de Troncoso. Fuente: Fotografía de Luisa Pardo, s.f

Cuando todavía estaba pendiente la aprobación del PBA correspondiente a Mondariz Balneario, el 31 de enero de 2018 visitó la población el vicepresidente de la Xunta de Galicia. Durante su estancia en la misma, el alcalde le mostró la fuente de Troncoso y le solicitó apoyo económico para recuperarla. El alcalde comentó que "la fuente de Troncoso es el inicio del mejor balneario de Europa, es un referente histórico y hay que protegerlo y cuidarlo y para eso necesitamos financiación" (Palleiro, 2018) (Figura 6).

Sin embargo, en 2019 la situación de la fuente seguía mostrando un deterioro creciente, con todos los problemas citados, pero en un estadio cada vez más avanzado. La magnífica verja, las barandillas y escaleras, todas de hierro forjado, estaban dañadas y oxidadas, mientras que el interior del pabellón mostraba una suciedad lamentable pese a la esporádica limpieza que una mugrienta fregona colocada bajo la escalera hacía presuponer que se realizaba. 


\section{Derrumbe de la techumbre y daños en el edificio}

Y llegó el fatídico día. El 9 de abril de 2019 Faro de Vigo informaba que "el tejado de una de las dos construcciones que conforman la edificación de la Fuente de Troncoso (Figura 7), ubicada al inicio del Paseo de Troncoso, en el Concello de Mondariz Balneario, se ha derrumbado en las últimas semanas por falta de mantenimiento" (Palleiro, 2019a).

El hundimiento (Figuras 8 y 9) había afectado a la techumbre del cuerpo en el que estaba ubicada la planta embotelladora, edificado en piedra, de unos $100 \mathrm{~m}^{2}$ de superficie y conformado por sótano y planta baja. Este edificio (parte izquierda de la citada Figura 7) contaba con una cubierta de teja plana a cuatro aguas. Anexo a éste se ubica el segundo cuerpo, algo mayor, también de planta rectangular, que consta de planta baja y sótano en el que está la fuente; la primera de ellas está limitada por una verja de forja mientras que la segunda alberga el manantial y la fuente propiamente dicha.

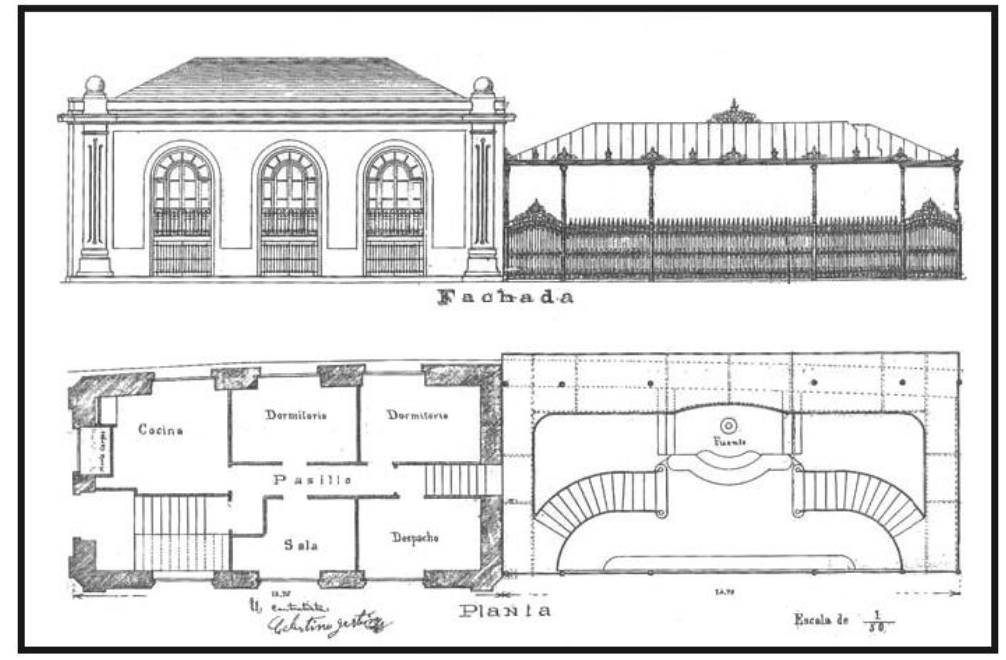

Fig. 7 Plano del proyecto de Palacios en Troncoso. Fuente: Pérez, 2005. Modificada

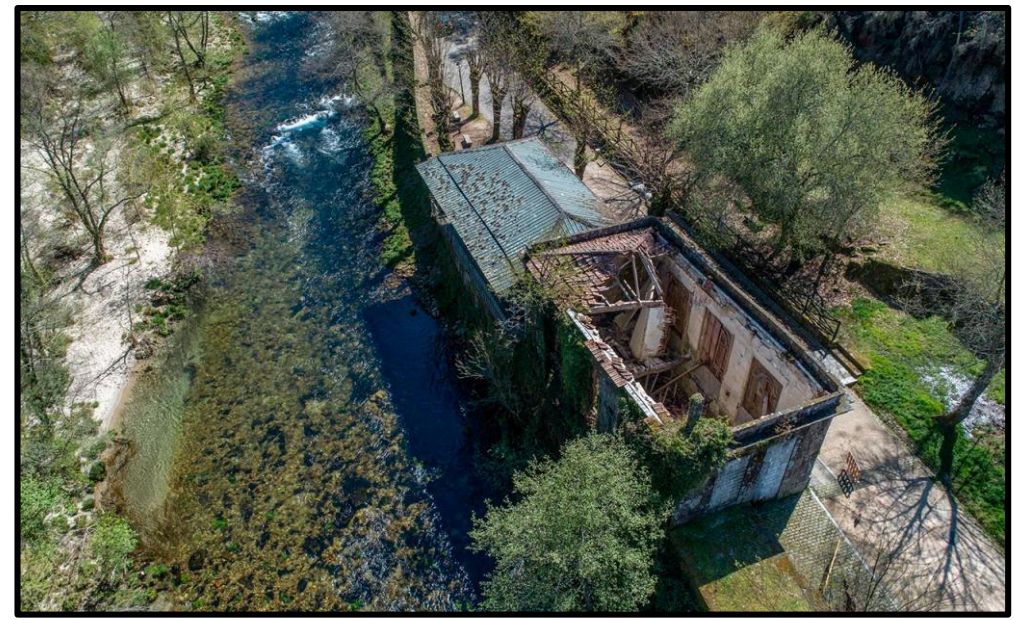

Fig.8 Vista aérea de Troncoso derruida desde el NO. Fuente: Palleiro, 2019 


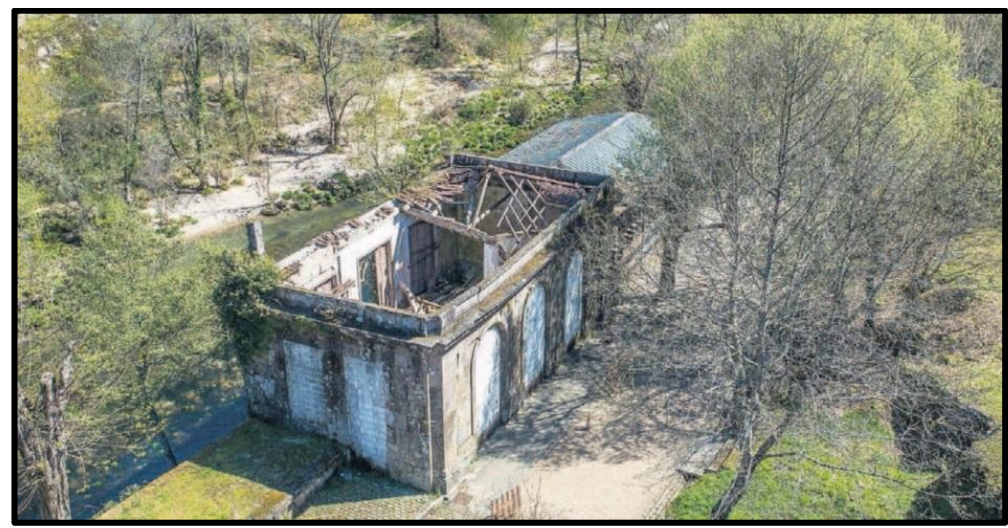

Fig. 9 Vista aérea de Troncoso derruida desde el SO. Fuente: Torres, 2019a

La situación del interior del inmueble era de completa ruina pues el techo, en su caída, había arrastrado la tabiquería interior y el piso de la planta baja que constituye el techo del sótano (Figura 10). Algunos muros exteriores también habían sido afectados por el derrumbe, desencajando varios sillares de su posición original o agrietando las juntas entre ellos (Figura 11).

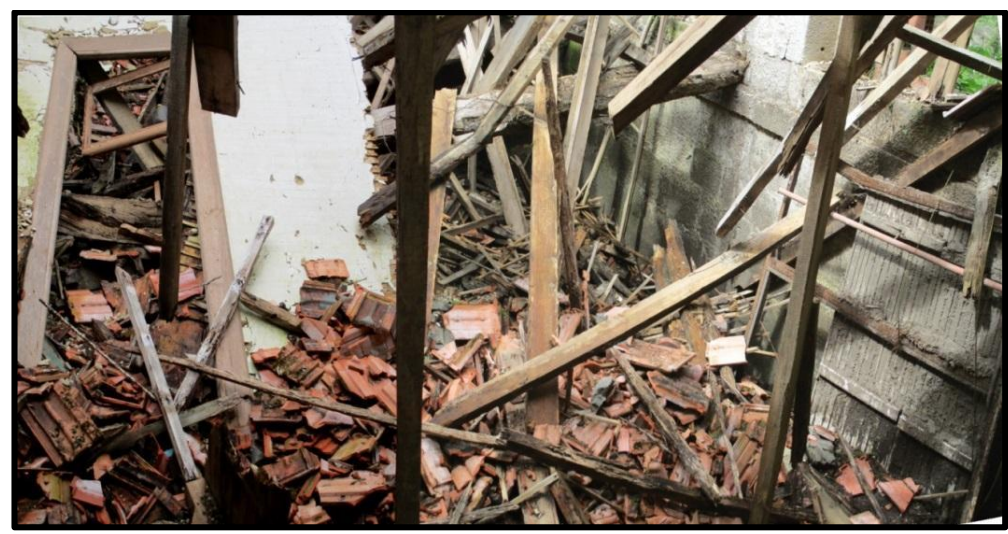

Fig. 10 Ruina interior de la planta de embotellado. Fuente: Archivo personal de los autores

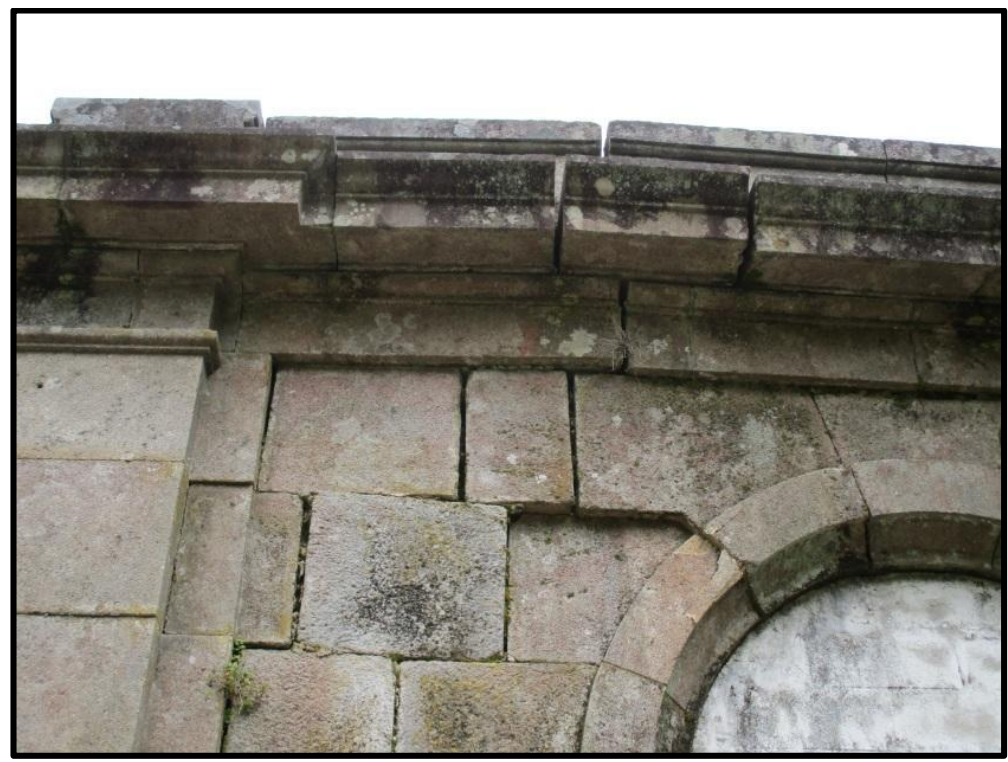

Fig. 11 Movimiento de sillares en el muro sur. Fuente: Archivo personal de los autores 
Afortunadamente el cuerpo de la fuente no había sido afectado por el hundimiento y podía ser utilizada en condiciones seguras por los agüistas. Las dos puertas de comunicación entre ambos cuerpos estaban cerradas por revestimientos muy precarios. Al conocerse el hecho, el arqueólogo y político local Alberte Reboreda instó por escrito a la Consellería de Cultura de la Xunta de Galicia a adoptar, a la mayor brevedad y con urgencia, las medidas necesarias previstas en la Ley 5/2016 del Patrimonio Cultural de Galicia, la cual permite la expropiación forzosa del bien si los propietarios incumplen el deber de conservarlo a fin de evitar su pérdida, destrucción o deterioro (Palleiro, 2019a). É mismo publicó el 18 de abril un artículo defendiendo esta misma vía (Reboreda, 2019).

Dando un toque de optimismo y esperanza a la salida de la situación, la Voz de Galicia adelantaba la buena noticia de que "Mondariz Balneario recuperará para su inventario municipal el manantial de Troncoso tras un siglo en manos privadas. Tanto la propiedad, que es la compañía Balneario de Mondariz como el alcalde, José Antonio Lorenzo, confirmaron ayer que hay un acuerdo de cesión que posibilitará "espero que en un plazo máximo de un mes» sentar a las partes ante el notario que dará fe de la donación" (Torres, 2019a).

Era una noticia excelente fruto del trabajo llevado a cabo por el regidor que, desde hacía meses, trabajaba en el documento de rehabilitación de la fuente, posiblemente la única obra debida a Antonio Palacios que está en una situación tan crítica. El alcalde confirmó que el edificio llevaba tiempo sin labores de mantenimiento y que cuando se firmase la cesión, el Ayuntamiento asumiría su rehabilitación integral, lo que de hecho implicaba haber obtenido la autorización de la Xunta de Galicia para hacerlo.

Tanto el Ayuntamiento como el Balneario de Mondariz, propietario de la fuente de Troncoso, llevaban un año trabajando en este trámite administrativo, pero habían tenido que completar el expediente recabando información. Según informaba la prensa "el alcalde mostró su gran interés por esta rehabilitación, que prosigue la línea iniciada con la recuperación de los jardines que, hace unos años, también pasaron a ser de titularidad municipal. "Ahora mismo estamos recuperando también el invernadero del antiguo hotel y el lavadero»" (Pontevedra, 2019).

El día 3 de mayo, la Consellería de Cultura de la Xunta de Galicia remitió un escrito al Balneario de Mondariz recordándole las obligaciones legalmente establecidas para los propietarios de bienes culturales, como era Troncoso, integrado en el patrimonio cultural de Galicia. Le avisaba de que, como tal, estaba obligado a conservarlo, mantenerlo y custodiarlo debidamente y debía evitar su pérdida, destrucción o deterioro, y que la dejación de estos deberes estaba tipificada como infracción y podía suponer la apertura de un proceso sancionador.

Por su parte, el Balneario de Mondariz aducía que en los últimos años había atravesado serios problemas financieros que condujeron a un concurso de acreedores del que había salido con mucho esfuerzo, y que en esa situación, su objetivo prioritario fue mantener el empleo de las más de 200 familias que dependían directamente del Balneario, empresa que constituía el motor casi exclusivo de toda la comarca.

El 12 de mayo, la prensa nacional se hacía eco del daño sufrido por la fuente. Informaba de que, según el alcalde, hacía casi dos años que se había empezado a negociar con el Balneario de Mondariz la cesión al consistorio, pero que el engranaje burocrático se movía con lentitud y el desplome del edificio se les había adelantado. El alcalde, con 36 años en el cargo, dijo que sabía, que intuía, que el edificio se vendría abajo pero que estaban pendientes de la tramitación de unos documentos que los propietarios aún no le habían entregado. Cuando los tuviera en su poder, el paso de Troncoso a ser de dominio público sería un hecho. La empresa propietaria, por su parte, aseguraba que la cesión se formalizaría antes del verano y sería por 20 años y confirmaba que el ayuntamiento se encargaría de su reforma y posterior mantenimiento (Pontevedra, 2019). También recientemente, la Asociación Hispania Nostra ha denunciado la calamitosa situación de la fuente. El 21 de mayo de 2019 confirmó que, pese al grado de protección integral que ostentaba el inmueble, presentaba un deficiente estado de conservación que se caracterizaba por: 
"1. La marquesina, dotada con barandillas modernistas de fundición, se encuentra en muy mal estado y sin cuidar.

2. El interior del edificio anexo, que se dedicó a obrador de embotellado de agua mineral y oficinas para el encargado de la fuente, acaba de desplomarse por completo, con la única salvedad de los muros portantes, a causa del abandono al que lo somete la propiedad" (Asociación Hispania Nostra, 2019).

Por ello, Hispania Nostra, en razón del mal estado de conservación y amenaza de ruina total de la fuente, la ha incluido en la Lista Roja de Patrimonio el citado día 21 de mayo de 2019. Cabe señalar que dicha institución define los elementos incluidos en la citada lista roja como "aquella parte de nuestro Patrimonio cultural y natural que se encuentra en abandono y en peligro. Recoge aquellos elementos del Patrimonio Histórico español que se encuentren sometidos a riesgo de desaparición, destrucción o alteración esencial de sus valores. Los criterios de inclusión en la Lista se basan, pues, en la importancia histórica y arquitectónica del elemento patrimonial en cuestión, en el estado en que encuentra y en el riesgo que recaiga sobre él, considerando no sólo sus valores objetivos sino, principalmente, los subjetivos que la sociedad le otorgue, de conformidad con el significado más actual de Patrimonio. La Lista Roja se elabora bajo supervisión de una comisión científica integrada por especialistas en la materia" (Asociación Hispania Nostra, 2019).

Es importante destacar el valor patrimonial que una asociación de expertos independientes como es Hispania Nostra atribuye a la fuente de Troncoso. En este sentido es de desear que la rehabilitación que parece se ha previsto efectuar, por tratarse de un bien patrimonial catalogado, se realice con los criterios recomendados por la UNESCO en estos casos para el patrimonio industrial (Carta de Nizhny Tagil, Principios de Dublín y Plan Nacional de Patrimonio Industrial del Ministerio de Educación, Cultura y Deporte) a fin de no desvirtuar irreversiblemente el bien protegido, en este caso, la fuente de Troncoso.

Pese a los compromisos adquiridos públicamente por el propietario y las administraciones, los vecinos de Mondariz-Balneario, sensibilizados con el penoso estado de la fuente de Troncoso decidieron el 24 de agosto de 2019 pasar a la acción. A tal fin, convocaron a los mayores de 18 años a un acto cívico de limpieza y adecentamiento de la fuente para el día siguiente. Actuaban, según propias palabras, "hartos del inmovilismo de las instituciones y de la propiedad del inmueble. (...) Pongamos manos a la obra para recuperarla, limpiarla y cuidarla" [traducido del gallego] (Anónimo, 2019a).

La portavoz del colectivo convocante recordaba que Troncoso era "un bien patrimonial catalogado y, por lo tanto, protegido por la Ley de Patrimonio que, además, representa los orígenes de nuestra villa y que, en estos momentos está en estado de semirruina" (Anónimo, 2019a).

En un comunicado a la opinión pública el colectivo de vecinos exponía que "asumiendo la ausencia de un gobierno de la Xunta o del Concello capaz de gestionar la problemática que existe con la fuente, los vecinos, y no sólo de Mondariz-Balneario sino de todo el territorio gallego, sensibilizados y que sienten como propia la defensa de los intereses del pueblo gallego y de su cultura, material e inmaterial, reconocemos la necesidad de defensa de nuestro patrimonio y nos consideramos más que facultados para promover la defensa de los intereses públicos de la villa" [traducido del gallego] (Anónimo, 2019a)

Como estaba previsto, el día 25 de agosto los vecinos acudieron a limpiar Troncoso (Figura 12). En total se reunieron cuarenta personas que, deseando que la fuente mantuviese su carácter público y fuese rehabilitada, sacaron de ella cubos llenos de lodo y sacos de hojas y basura. Para mantener la acción prevista, los vecinos han constituido una comisión de trabajo (Torres, 2019b). 


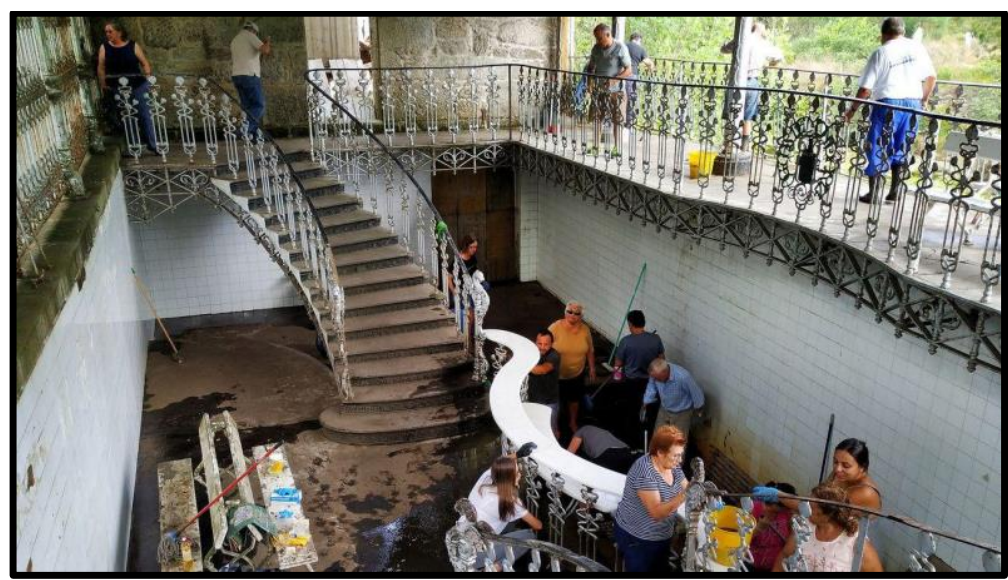

Fig. 12 Vecinos limpiando el interior de la fuente de Troncoso. Fuente: (Torres, 2019b)

Muy pronto, otros colectivos salieron en apoyo, como la Facultad de Historia de la Universidad de Vigo que, con fecha 20 de septiembre, comunicaba su apoyo para que se aplicase con urgencia las medidas que contenía la Ley de Patrimonio de Galicia de 2016 a fin de evitar el colapso y la ruina inminente de la fuente de Troncoso (Palleiro, 2019b). Por su parte, los vecinos dieron un paso más constituyéndose en plataforma popular el 21 de septiembre, con el objetivo de recuperar la fuente (SOS Fonte de Troncoso, 2019a).

Ante el peligroso estado de la estructura del edificio, el Ayuntamiento de Mondariz mandó vallar y cerrar el acceso a la fuente el día 24, mientras que los vecinos insistían en que vigilarían que se diesen los pasos a que obligaba la citada Ley, que debían rematar con la rehabilitación y puesta en valor de la fuente, añadiendo que no dejarían que su patrimonio desapareciera detrás de una valla (SOS Fonte de Troncoso, 2019b). Días después, el 27, la plataforma vecinal criticaba la medida por considerar que, pese al abandono, entrar a la fuente no ofrecía peligro de derrumbe y más sin iniciar el apuntalamiento provisional del edificio ni las obras de rehabilitación que exigían (Palleiro, V. (2019c).

Como era de esperar, la Universidad de Vigo aseguró su apoyo cuando el día 6 de octubre, la decana de la Facultad de Historia urgía la rehabilitación de Troncoso considerando que daba igual de quién fuera la responsabilidad de hacerlo pues lo importante era que detuvieran ya su deterioro (Anónimo, 2019b). Poco después, el día 10, el alcalde de Mondariz Balneario dio a conocer una mala noticia: las negociaciones iniciadas en 2016 entre el Balneario de Mondatriz y el Ayuntamiento no habían llegado a buen fin, no se había producido acuerdo, y descartaba la cesión de Troncoso al municipio. El alcalde aseguraba que la administración local había informado a la Dirección Xeral de Patrimonio del estado de la fuente, para que actuase, constándole que la Xunta de Galicia ya se había puesto en contacto con la propiedad para advertirle de sus deberes. En paralelo con esta situación, la Sala de Medio Ambiente de la Fiscalía General del Estado estaba siguiendo el caso para valorar la posibilidad de abrir diligencias penales. Finalmente, el alcalde comentó que, como la fuente no avisaba si iba a caer, la vallaron por seguridad, aunque advirtió que, al ser una propiedad privada, el municipio no podía impedir el acceso a ella (Palleiro, V. (2019d). La última noticia sobre este asunto (10 de noviembre) es que la dirección de la Escola Superior de Conservación e Restauración de Bens Culturais de Galicia visitó la fuente invitada por los vecinos de Mondariz Balneario, con lo que pudo observar in situ cuál era el estado del edificio de Palacios. A petición de la plataforma SOS Fonte de Troncoso, elaboró un informe técnico que la plataforma iba a remitir de inmediato al Ayuntamiento, a la Consellería de Cultura e Turismo de la Xunta de Galicia y al Fiscal General del Estado. En dicho informe, firmado por la directora del centro, se solicitaba "aplicar medidas de protección activas que garanticen la conservación de los bienes protegidos que formen parte del patrimonio cultural de Galicia si los titulares de los mismos no lo hacen" y exigía la toma de medidas urgentes (Porto, 2019). 
En conclusión, la demandada rehabilitación de la fuente de Troncoso se ha complicado a última hora, aunque la intervención de la Xunta de Galicia y de la Fiscalía General del Estado podría acelerarla. Devolverla a su pasada plenitud no será fácil ni barato dado el estado de deterioro que presenta, pero, pese a ello, continúa proporcionando a los numerosos agüistas que se acercan a ella las cantidades de agua mineral que, con escasas interrupciones, ha venido proporcionando desde hace 150 años.

\section{Conclusiones}

Pese a que las aguas de la fuente de Troncoso tuvieron en el pasado una importancia singular para el municipio de Mondariz Balneario pues constituyeron un foco de atracción para agüistas provenientes de toda España, Portugal, el Reino Unido y otros países europeos y hasta del continente americano, su ubicación y lejanía del establecimiento balneario impidieron que adquiriera el protagonismo que sí tuvo su fuente hermana, Gándara. No obstante, el paseo diario desde el Balneario de Mondariz $u$ otros hoteles hasta Troncoso para tomar sus aguas era una actividad practicada por la mayor parte de los agüistas alojados en la villa. La calidad de sus aguas, similares a las de Gándara, sigue atrayendo a las personas que viven en su entorno, constituyendo visita obligada de aquellos que padecen dolencias para las que resulta beneficiosa el agua de la fuente.

Construida en 1910, la fuente de Troncoso constituye un magnífico edificio que alberga la propia surgencia de agua y, que además, dispone de un anexo antiguamente dedicado a planta embotelladora. Fue diseñado y construido por el eminente arquitecto Antonio Palacios. Con los años la fuente se fue deteriorando, proceso que, posiblemente, se aceleró tras el incendio que asoló el balneario en 1973 y provocó su cierre temporal. Pese a ello, la afluencia de agüistas ha sido y es continua. Este proceso de degradación paulatina ha seguido su curso sin que el propietario ni las administraciones públicas se hayan decidido a intervenir para atajar la situación. Cierto es que, a partir de 2002, unos y otros propusieron algunas medidas conducentes a devolverle el pasado esplendor, pero ninguna cuajó. Incluso fue declarado bien patrimonial protegido, pero tampoco fue suficiente para mejorar su situación. Y un buen día, se derrumbó parte de la techumbre causando la ruina de la parte del edificio que se dedicó a planta embotelladora. En este proceso resulta descorazonador cómo la paulatina degradación ha ido acompañada de variadas propuestas de rehabilitación y protección que, por no aplicarse o ser inefectivas, no han redundado en nada positivo. El caso presente documenta y demuestra cómo el descuido y el desinterés, real u obligado por las circunstancias, del propietario y de las administraciones públicas involucradas en mantener un bien, puede conducir a su ruina, situación en la que tiene mucho que ver el fárrago legislativo que la propia administración ha propiciado el cual está demostrando ser poco adecuado para resolver situaciones como la presente. Es más, ni siquiera garantiza la protección que, teóricamente, proporciona a un bien cultural amparado por ella cuando hacen presencia la desidia, el desconocimiento o la falta de medios de control que comprueben si son aplicadas las normas.

Los contactos entre el propietario y la administración local han fracasado pero nuevos intervinientes autonómicos y nacionales tal vez podrían acelerar el final de la historia y la rehabilitación de la fuente. Los vecinos usuarios de la fuente y amantes de conservar su patrimonio cultural, hartos de la ineficacia de las instituciones que tienen que resolver el problema, han decidido iniciar un movimiento popular encaminado a limpiar, adecentar y cuidar la fuente para contrarrestar su deterioro que ya acaba de realizar su primera intervención en Troncoso. Puesto que las palabras no han sido efectivas, tal vez ésta sea la forma de llamar la atención de aquellos que tienen la obligación legal de actuar para provocar, siquiera por vergüenza, que aceleren la resolución del caso.

Al respecto cabe señalar que la situación comentada se presenta frecuentemente, con sus particularidades, en bienes patrimoniales repartidos por toda España que incluso están protegidos por legislación estatal de rango superior, como es el caso de los Bienes de Interés Cultural (BIC). La situación descrita es la punta del iceberg de una situación que demanda mayor atención por parte de las autoridades, que no deben esperar a que las fuerzas vecinales tomen la iniciativa reivindicativa, acción que, por otra parte, no debe incluir la intervención sobre el bien, que debe ser objeto de especialistas. 


\section{Bibliografía}

[ANÓNIMO]. (Río Tea, 2006a). Archivo fotográfico Flick.

https://www.flickr.com/photos/marquesol1/24069630881/in/photostream/ (Consulta: 04/05/2019).

[ANÓNIMO]. (Río Tea, 2006b). Archivo fotográfico Flick.

https://www.flickr.com/photos/marquesol1/24126137846/in/photostream/ (Consulta: 04/05/2019).

[Fotografía de Luisa Pardo]. (Mondariz, s.f). Archivo fotográfico Flick.

https://www.flickr.com/photos/marquesol1/13756755255/in/photostream/ (Consulta: 20/05/2019).

ANÓNIMO (2011). A Fonte de Troncoso vai ter que agardar. Galicia Confidencial, 7 de mayo de 2011. http://www.galiciaconfidencial.com/noticia/7770-fonte-troncoso-vai-ter-agardar (Consulta: 22/07/2019).

ANÓNIMO (2014). Balneario de Mondariz entra en concurso de acreedores. El establecimiento termal pontevedrés trabaja con "normalidad" y una "elevada ocupación". Faro de Vigo, 28 de noviembre de 2014. https://www.farodevigo.es/economia/2014/11/28/balneario-mondariz-entra-concurso-

acreedores/1139834.html (Consulta: 02/07/2019).

ANÓNIMO (2015). Balneario de Mondariz supera el concurso en menos de un año. Atlántico, 10 de octubre de 2015. https://www.atlantico.net/articulo/economia/balneario-mondariz-supera-concurso-menos-

ano/20151010014200496236.html (Consulta: 30/06/2019).

ANÓNIMO (2019a) Vecinos de Mondariz-Balneario salen al rescate de la Fonte de Troncoso. La Voz de Galicia, 24 de agosto de 2019. https://www.lavozdegalicia.es/noticia/vigo/mondariz-

balneario/2019/08/24/vecinos-mondariz-balneario-salen-rescate-fonte-troncoso-obrapalacios/0003_201908V24C4996.htm (Consulta: 24/08/2019).

ANÓNIMO (2019b) La decana de la Facultad de Historia urge su rehabilitación. Faro de Vigo, 6 de octubre de 2019. https://www.farodevigo.es/comarcas/2019/10/06/decana-facultad-historia-urgerehabilitacion/2181780.html (Consulta 10/06/2019).

CONCELLO DE MONDARIZ BALNEARIO (s/f). Fonte do Troncoso no río Tea. http://mondarizbalneario.es/web/historia/. Consulta: 04/05/2019.

CONSELLO DA CULTURA GALEGA (2015). Informe sobre a unidade do conxunto do Hotel-Balneario de Mondariz. Santiago.

CONSULTORA GALEGA, S.L.U. (2016a). Modificación puntual $n^{\circ} 3$ del POMR del Ayuntamiento de Mondariz Balneario. Memoria justificativa. Tomo II. http://mondarizbalneario.es/web/docgrandes/MEMORIA\%20XUSTIFICATIVA\%20CASTELLANO\%20CON\%20PLANOS_cast.pdf (Consulta: 21/07/2019).

CONSULTORA GALEGA, S.L.U. (2016b). Modificación puntual $n^{\circ} 3$ del POMR del Ayuntamiento de Mondariz Balneario. Tomo III. Estudio ambiental estratégico. http://mondarizbalneario.es/web/docgrandes/ESTUDIO\%20IMPACTO\%20AMBIENTAL\%20CON\%20PLANOS_cast.pdf (Consulta: 21/07/2019). 
FUNDACIÓN MONDARIZ BALNEARIO (2009). La Fundación Mondariz Balneario distingue a Emilia Pardo Bazán como "embajadora de Mondariz" [Comunicado de prensa]. http://www.aguasdemondariz.com/en/node/302_(Consulta: 11/07/2019).

FUNDACIÓN MONDARIZ BALNEARIO (2011). Memoria de actividades 2010. [diaspositivas de PowerPoint]. https://studylib.es/doc/8570979/archivo-recuperado-1---fundaci\%C3\%B3n-mondariz-balneario (Consulta: 20/05/2019).

GÓMEZ DE BEDOYA, P. (1772). Descripción de 54 fuentes minerales del Reyno de Galicia. Manuscrito.

HISPANIA NOSTRA (s.f). Lista roja del patrimonio. https://listarojapatrimonio.org/ (Consulta: 07/08/2019).

INTERNATIONAL COUNCIL ON MONUMENTS AND SITES (ICOMOS) y THE INTERNATIONAL COMMITTEE FOR THE CONSERVATION OF THE INDUSTRIAL HERITAGE (TICCIH) (2011) Principles for the Conservation of Industrial Heritage Sites, Structures, Areas and Landscapes "The Dublin Principles». http://www.sedpgym.es/cartas-unesco (Consulta: 19/07/2019).

MADOZ, P. (1848). Diccionario Geográfico Estadístico Histórico de España y sus posesiones de Ultramar. Madrid.

MERZ ARQUITECTOS (2014). Propuesta de rehabilitación de la Fuente de Troncoso, 2011. https://www.behance.net/gallery/11218233/TRONCOSO. (Consulta: 20/06/2019).

MINISTERIO DE EDUCACIÓN, CULTURA Y DEPORTE (2015) Plan Nacional de Patrimonio Industrial. https://sede.educacion.gob.es/publiventa/descarga.action?f_codigo_agc=15114C (Consulta: 19/07/2019).

ORCHE, E., AMARÉ, M.P. y ORCHE, M.P. (2015). La fuente de Troncoso, origen del Balneario de Mondaríz: un patrimonio cultural y minero abandonado a su suerte. En J.M. MATA-PERELLÓ, M. HUNT y E. ORCHE, E. (eds.), Patrimonio geológico y minero: de la investigación a la difusión. Cáceres: SEDPGYM-Ayuntamiento Logrosán, p. 291-322.

PALLEIRO, V. (2018). La Fuente de Troncoso necesita mejoras. Faro de Vigo, 31 de enero de 2018. https://www.farodevigo.es/comarcas/2018/01/31/fuente-troncoso-necesita-mejoras/1829064.html (Consulta: 20/07/2019).

PALLEIRO, V. (2019a). El tejado de la Fuente de Troncoso, obra de Antonio Palacios, sucumbe por su abandono. Faro de Vigo, 9 de abril de 2019. https://www.farodevigo.es/comarcas/2019/04/09/tejado-fuentetroncoso-obra-antonio/2084315.html (Consulta: 20/07/2019).

PALLEIRO, V. (2019b) Universidad de Vigo y vecinos de Balneario instan a Patrimonio a salvar la Fonte de Troncoso. Faro de Vigo, 20 de septiembre de 2019.

https://www.farodevigo.es/comarcas/2019/09/20/universidade-vigo-vecinos-balneario-instan/2173050.html (Consulta 21/09/2019).

PALLEIRO, V. (2019c) Mondariz Balneario cierra con vallas el acceso a la Fonte de Troncoso. La plataforma popular critica la medida por no existir riesgo de derrumbe. Faro de Vigo, 27 de septiembre de 2019. 
https://www.farodevigo.es/comarcas/2019/09/27/mondariz-balneario-cierra-vallas-acceso/2176845.html (Consulta 27/09/2019).

PALLEIRO, V. (2019d) Mondariz Balneario descarta la cesión de la Fonte de Troncoso tres años después de solicitarla. Faro de Vigo, 10 de octubre de 2019. https://www.farodevigo.es/comarcas/2019/10/06/mondarizbalneario-descarta-cesion-fonte/2181781.html (Consulta 10/10/2019).

PÉREZ, Y. (2005). El balneario de Mondariz. La creación de un lugar (1873-1931). Tesis de Doctorado. Universidad de Santiago de Compostela.

PONTEVEDRA, S.R. (2019). Un edificio del arquitecto Antonio Palacios se derrumba en Galicia. El País, 12 de mayo de 2019. https://elpais.com/cultura/2019/05/08/actualidad/1557272157_869160.html (Consulta: 20/07/2019).

PORTO, G. (2008). Presentan un plan de recuperación de las márgenes del Tea a los fondos Feder. Faro de Vigo, 21 de febrero de 2008. https://www.farodevigo.es/comarcas/3272/presentan-plan-recuperacionmargenes-tea-fondos-feder/202093.html (Consulta: 14/07/2019).

PORTO, G. (2010). Problemas en la estructura obligan al cierre de una fuente mineral de Mondariz. Faro de Vigo, 6 de agosto de 2010. https://www.farodevigo.es/comarcas/2010/08/06/problemas-estructura-obligancierre-fuente-mineral-mondariz/461853.html (Consulta: 12/08/2019).

PORTO, G. (2019). La Escola de Restauración pide medidas urgentes para salvar la Fuente de Troncoso. Faro de Vigo, 10 de noviembre de 2019. https://www.farodevigo.es/comarcas/2019/11/10/escolarestauracion-pide-medidas-urgentes/2200035.html (Consulta 10/11/2019).

REBOREDA, A. (2019). SOS pola Fonte de Troncoso. Faro de Vigo, 18 de abril de 2019. https://www.farodevigo.es/comarcas/2019/04/09/tejado-fuente-troncoso-obra-antonio/2084315.html (Consulta: 10/08/2019).

RUIZ, M.; GARCÍA, A.; CARRETERO, M.; VILLAFRANCA, B.; TABOADA, M. (1877) Anuario Oficial de las Aguas Minerales de España. Tomo I. 1876-1877. Madrid.

SOS FONTE DE TRONCOSO (2019a).

https://www.facebook.com/pg/SOSFonteDeTroncoso/posts/?ref=page_internal (Consulta 21/09/2019).

SOS FONTE DE TRONCOSO (2019b).

https://www.facebook.com/pg/SOSFonteDeTroncoso/posts/?ref=page_internal (Consulta 24/09/2019).

THE INTERNATIONAL COMMITTEE FOR THE CONSERVATION OF THE INDUSTRIAL HERITAGE (TICCIH) (2003) Carta de Nizhny Tagil sobre el patrimonio industrial. http://www.sedpgym.es/cartas-unesco (Consulta: 19/07/2019).

TORRES, M. (2019a). Balneario de Mondariz cede al Concello un edificio de Palacios deteriorado. La Voz de Galicia, 9 de abril de 2019. https://www.lavozdegalicia.es/noticia/vigo/2019/04/09/balneario-mondariz-cedeconcello-edificio-palacios-deteriorado/0003_201904V9C6991.htm (Consulta: 12/08/2019). 
TORRES, M. (2019b). Retiran bidones de lodos y basura de una fuente de Antonio Palacios. La Voz de Galicia, 26 de agosto de 2019. https://www.lavozdegalicia.es/noticia/vigo/2019/08/26/retiran-bidones-lodosbasura-fuente-antonio-palacios/0003_201908V26C2995.htm (Consulta: 26/08/2019).

XUNTA DE GALICIA (1997). Orden de 10 de junio de 1997 por la que se reconoce de interés gallego y se ordena la inscripción en el Registro de Fundaciones de Interés Gallego la Fundación Mondariz-Balnerario. Diario Oficial de Galicia No 118, de 20 de junio de 1997.

XUNTA DE GALICIA (2016). Ley 5/2016. Ley del patrimonio cultural de Galicia. Diario Oficial de Galicia No 92, de 16 de mayo de 2016.

XUNTA DE GALICIA (2018). Mapa de afeccions territoriais. Hoja 0224A-0206. Plan Básico Autonómico. Planos a escala 1:10.000. Mondariz-Balneario. https://cmatv.xunta.gal/seccionorganizacion/c/CMAOT_SX_de_Organizacion_do_Territorio_e_Urbanismo?content=SX_Ordenacion_Territori o_Urbanismo/Estado/seccion.html\&std=plan_basico_autonomico.html. (Consulta: 15/07/2019). 